urine, and 22 from the unboiled, besides a few milligrammes which adhered to the sides of the test-tube in the unboiled urines with too great tenacity to be got off by washing. Again, while examining the precipitate of uric acid in the first experiment I have mentioned in this paper, I noticed that while the crystals which precipitated naturally were clear and colourless, yet after the fluid was boiled, though they did not dissolve, they presented more or fewer granules on their surface, similar to the globules of gas developed in uric acid crystals precipitated by nitric acid; for on adding the latter acid to a series of test-tubes containing 2 cc. of urine each, it will be found that if from four to twelve drops or so are used the uric acid crystallises out in twentyfour hours, but the crystais are granular. If a larger quantity of $\mathrm{HNO}_{3}$ is used, they do not come out at all, because they are broken up and dissolved. The same thing was seen in hot weather on comparing two specimens of uric acid on a glass side, one of which had been protected by a covering glass, the other not, but simply protected from dust. When examined the next day, the crystals in the one were clear, but in the other granular; so also after warming a glass slide with a precipitate of uric acid on it, the crystals clear at first, appearing intensely granular. I have verified these results by repeated observation, so that I am thorougly convinced of their correctness, and $I$ would add that this oxidation seems to begin within the bladder itself, for $\mathrm{CO}_{2}$ and $\mathrm{N}$ are found free in urine, and yet comparatively no $\mathrm{O}$, which ought to be the case if these gases were derived from the blood; they are, however, well known to be the products of the oxidation of uric acid, and it therefore would appear that it is to uric acid and not to mucus we must look for an explanation of the subsequent changes in urine; indeed, I regard the function of mucus as protective, for by increased secretion it will prevent any evil result from the irritation of urine decomposing in a paralysed bladder. During the whole period of decreasing acidity the urea seems to remain unchanged; it then begins to decompose, but by what process is not yet clear. The ordinary theory that a peculiar ferment, probably an organic being, causes it to assume two molecules of water and become carbonate of ammonia is wholly unproved; but without doubt, whether it be thus or by a process analogous to the continuous etherification process that carbonate of ammonia is formed, its discovery must throw much light on one of the most obscure departments of physiology. The period at which the acidity of urine ceases varies very greatly, both with the temperature of the air and with the form of the vessel in which it is contained. Small quantities of urine in a test-tube become alkaline very readily, and the more so if not originally very acid; indeed, the addition of $\mathrm{HCl}$ or other strong acid will delay the alkaline fermentation of urine indefinitely. If the urine be put in a tall, narrow glass offering not more than a square inch of surface, it may remain acid for a fortnight even in warm weather; but the temperature of the air varies from hour to hour, rising towards midday and falling afterwards, and I have often noticed the temperature of the urine rising every hour in a corresponding manner, but always $1^{\circ}$ or $1.5^{\circ} \mathrm{C}$. lower in the forenoon than the air. While, therefore, the urine in a vessel follows the changes of the atmosphere, it is always an hour or two behind, probably from the greater specific heat of water. Even in these cases, therefore, the small surface exposes incessantly fresh particles of contained uric acid to oxidation, and thus hastens its ultimate decomposition.

Thirdly.-It has been much debated whether any increase of acidity takes place after meals, and Bence Jones and Roberts especially have strongly denied this. Now though my experiments entirely agree with theirs in that $I$ have invariably found $10 \mathrm{cc}$. of the morning urine contain more acid than $10 \mathrm{cc}$. at any time after breakfast, yet $I$ think the conclusion they draw is not valid. The proper stimulus of the bladder is distension, and it seems therefore that in determining the acidity of the morning urine, and comparing it with that after food, its quantity and the time of its secretion must be taken into account. When this is done I think that there can be no question that the acidity of the urine is largely increased by food. The mean of twenty experiments on urina sanguinis gave the acidity as 17 , as compared with 14 for the same number on urina cibi; but the specific gravity was also diminished in the latter case, and the phosphates were nearly halved in quantity; the time of secretion of equal quantities was not more than half. It appears to me, therefore, that while the acidity of urine is always bigher in the morning than at any other time for a given quantity of urine, yet this effect is entirely due to its greater concentration and longer period of secretion, and that the amount of acid, absolutely, though not relatively to the water, is largely increased by food.

\section{ON VENOUS ANEURISM AND ADAPTATION OF TISSUES.}

By A. VANS BEST, M.D., F.R.C.S.

IN the spring of this year I was asked to examine a swelling upon a girl's forearm. Her age was about fourteen; she was quite healthy; and the history of the swelling was obscure. I found a very peculiar tumour, larger than a walnut, just over the anterior superficial radial vein. It was emptied by pressure on the distal side. There was no pain, except a slight undulatory throbbing. I diagnosed it as a dilated sacculated valve of the vein, and removed it, tying the vein above and below.

The appearance of the sac after being cleaned out was exactly like the interior of an auricle; the capacity was larger than the point of a thumb; and the walls showed trabeculæ, and even muscular fibre, under the microscope. The wound healed well.

I could elicit no history of injury or puncture, and it is difficult to trace how such a tumour occurred. It was different from a varicose thrombus occurring in the lower extremity. It was a case of pure venous aneurism, with modified and organised walls; and, from its structure, might have had contractile power. There was no arterial communieation, and only one dilatation of the vein. The preparation well shows the interior of the tumour.

Adaptation of tissue, also, is seen wonderfully at the neck of the bladder and in the perineum. In the event of the bursting of the membranous portion of the urethra, occasioned by old stricture, we not unfrequently find, after all the immediate dangers have been combated, that a deputy bladder has formed, and the loose cellular tissue become so matted together and covered by a pseudo-mucous membrane as to form really a safe reservoir where the surplus water can be confined. This is emptied generally by an instrument or by manual pressure; but it also of ten bas contractile force, as the patient is aware of its emptying and filling. Great adaptation of tissue must have occurred in these cases. In one, after external section straight to the bladder, I cured the patient of his mass of cartilaginous strictures, but his deputy bladder continued to be evacuated by pressure inside the left tuberosity of the ischium, and when once it flowed he strained hard. In another case the whole calibre of the urethra (membranous) was fusiform, exactly like Aveling's transfusion bag. This anterior bladder was constantly emptied by the patient, who carried a flexible catheter, which relieved him for twenty minutes. With great difficulty I got an instrument into the true bladder, but without any benefit, and had to trust to suppositories to allay irritability.

Other examples of adaptation of mucous membrane and skin are to be seen in the cure of severe cases of ectropion and entropion; also during the cure of fistula lachrymalis, or after division of Steno's duct; in the lifting of the middle portion of the upper lip to form a columna, and in sepa rating the cheek from the jaw to obtain material for a fresh lip in epithelioma.

Aberdeen.

\section{IMPROVED DOUBLE STETHOSCOPE.}

\section{BY CARTWRIGHT REED, M.D.}

THE improvements claimed for this instrument over others of its class are as follows: -1 . The ends of the elastic tubing (A $A$ and $B$ B) are visible. At first impression this may not be considered an improvement; but I was in. formed by an eminent auscultator that on first using the 
double stethoscope he fancied he was slightly deaf with one ear, when, by accident, he discovered that one tube of the stethoscope was stopped, or nearly so, and on taking the tubing ont it was found that the elastic forming the tubing had puckered-in during the manipulation of the instrument, thus preventing the free progress of sound to the ear. 2. The lower ends of the elastic tubing (B $\mathbf{B}$ ) are brought down close to the walls of the chest when the instrument is in nse. 3. The instrument is more portable, for it can be divided at $\triangle \mathrm{A}$ (as seen in Fig. 1) by unscrewing the rings ( $(\mathrm{c})$, and when so divided can be conveniently carried in
Fig. 1.

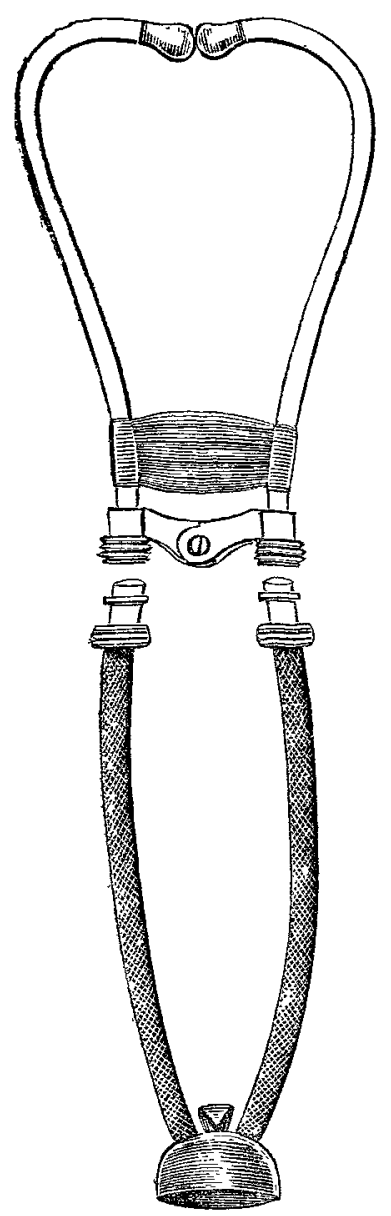

Fiศ. 2.

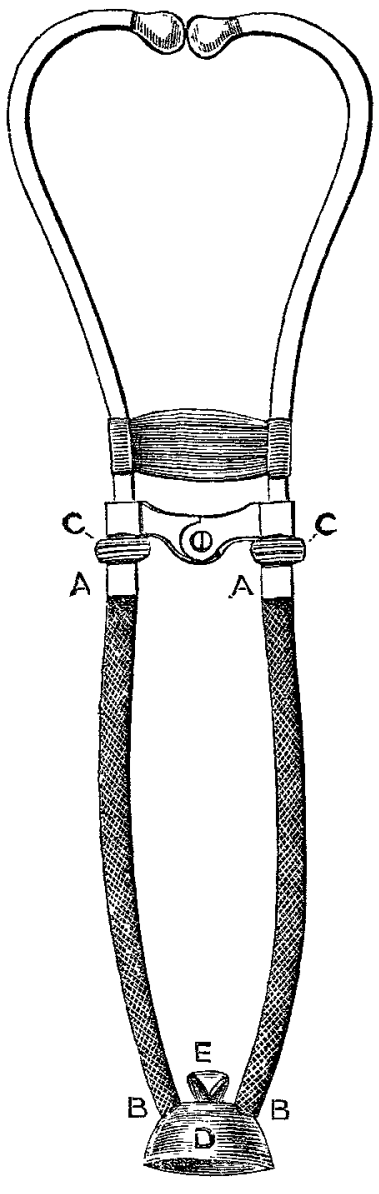

the breast-coat pocket. 4. A little cup (D) is introduced instead of the trumpet-shaped piece usually seen on most double stethoscopes. The little $\mathrm{knob}(\mathrm{E})$ is intended for the manipulator to hold the cup in position by pressure of either thumb or one finger; and, to do away with any friction-sound which might be produced by the dry finger or thumb, the knob is covered with soft elastic. The present double stethoscope must be held in position between the thumb and fingers. The old single stethoscope is held in its place by the physician's head at one end and the patient's chest at the other end; and should the walls of the chest be thin or the ribs projecting, this proceeding is sometimes attended with considerable inconvenience, if not with actual pain.

I may suggest that it would be beneficial to the profession at large if the College of Physicians, on the one hand, and the College of Surgeons, on the other, were to have a rule (like that having reference to new works sent to the British Museum) for all new inventions applying to medicine and surgery to be submitted to them, and, if found worthy by competent authorities, for the new instruments to be placed with their classes in a section of the museums of these Colleges, to enable both students and practitioners to see them; and every now and then for one of the professors of the schools to have access to them for demonstration before his class. By this means the student would be kept informed of the progress of these necessary adjuncts to the art of medicine and science and art of surgery.

\section{d}

or

\section{HOSPITAL PRACTICE,} BRITISH AND FOREIGN.

Nulla autem est alia pro certo noscendi via, nisi quamplurimas et morborum et dissectionum historias, tum aliorum, tum proprias collectas habere, et inter se comparare.-MoBgAGII De Sed. et Caus. Morb., lib. iv. Procmium.

\section{MIDDLESEX HOSPITAL.}

\section{SUCCESSFUL TREATMENT OF A CASE OF UNUNITED FRACTURE OF THE TIBIA AND FIBULA.}

(Under the care of Mr. Geonge Lawson.)

THE following notes, for which we are indebted to $\mathrm{Mr}$. Arthur Tomes, house-surgeon, are a continuation of the case reported at page 343 . The facts are briefly as follows: On June 30 th the patient fell from a scaffolding a distance of twenty feet, and struck the back of his head. There was a starred wound of the scalp, and the bone over the occiput was laid bare, but no fracture could be made out. At the same time the tibia and fibula were broken in the manner described below. The patient was unconscious on admission, and remained in this state till the 6 th of July, when he appeared to recognise his wife. It was not, however, till the 16th of July that he became fully conscious, and even then he suffered from a partial loss of memory. The wound in the scalp readily healed, but the fracture of the bones of the leg showed very little signs of repair. The case seems to have been one of retarded union, rather than one of non-union. This explanation appears the more plausible when it is borne in mind that the splint was changed twice in three weeks. The MacIntyre splint which was first applied was removed on July 6 th, because the patient was so restless that the apparatus could not be retained in its proper position. On July 20 th the splint was again changed, the ordinary Cline's splint being substituted for the Liston's long splint that was applied on the 6th. Although some callus was thrown out, proper reparative action did not take place till the limb was kept in a state of complete rest, and the fractured bones made per fectly immobile by neans of a strong plaster-of-Paris mould.

The fracture of the right tibia in the lower third was oblique, the upper fragment overriding the lower, and projecting forwards. The fibula was also broken in the same situation, and there was about one inch shortening. The limb was put up in a M'Intyre's splint, and ice bags were applied to the leg. On July 6ch the M'Intyre's splint was changed for a Liston's long splint on the outside and a Cline's splint on the inside. On examining the leg on July 20 th there was found to be no sort of union, and as Liston's splint was somewhat irksome, the fracture was put up in an ordinary Cline splint. At the end of a fortnight the leg was examined, and, although some callus bad been thrown out, the bones were still ununited. Accordingly, on August 4th (5th week), it was determined to try the effect of encasing the whole limb from the middle of the thigh to the toes in a solid mould of plaster-of-Paris, to ensure complete rest and to keep the fractured ends in perfect apposition, and at the same time to restrain the action of the muscles. The leg was first enveloped in a thin layer of cotton wool, over which a loose bandage was applied, and the whole was then surrounded by a plaster-of-Paris mould several inches in thickness. As the plaster set a great deal of heat was given out, which produced some discomfort, but this soon passed off, and the patient lay without suffering further inconvenience, except that produced by the weight of the splint. The base of the mould was made broad and flat, to prevent tilting or rolling of the leg. On Sept. 5 th the plaster was removed by being carefully split up in various directions, and the bandage cut through, when the bones were found to be firmly united. The skin had not suffered in the least. 